\title{
Effects and potential mechanisms of rapamycin on MPTP-induced acute Parkinson's disease in mice
}

\author{
Guifang Zhang ${ }^{1}$, Lishi Yin ${ }^{2}$, Zhenchun Luo ${ }^{1}$, Xuemei Chen ${ }^{1}$, Yanping He ${ }^{1}$, Xie Yu $^{1}$, Ming Wang ${ }^{1}$, \\ Fengwei $\operatorname{Tian}^{3}$, Haiyan Luo
}

${ }^{1}$ Department of Emergency and the Intensive Care Unit, Chongqing Hospital of Traditional Chinese Medicine, Chongqing, China; ${ }^{2}$ Department of Hepatopathy, Chongqing Hospital of Traditional Chinese Medicine, Chongqing, China; ${ }^{3}$ Department of acupuncture and moxibustion, Chongqing Hospital of Traditional Chinese Medicine, Chongqing, China; ${ }^{4}$ Department of Neurology Medicine, The Second Affiliated Hospital of Chongqing Medical University, Chongqing, China

Contributions: (I) Conception and design: Z Luo, H Luo; (II) Administrative support: G Zhang, L Yin; (III) Provision of study materials or patients: None; (IV) Collection and assembly of data: G Zhang, L Yin, Z Luo, X Chen, Y He; (V) Data analysis and interpretation: X Yu, M Wang, F Tian, H Luo; (VI) Manuscript writing: All authors; (VII) Final approval of manuscript: All authors.

Correspondence to: Zhenchun Luo. Department of Emergency and the Intensive Care Unit, Chongqing Hospital of Traditional Chinese Medicine, Chongqing 400021, China. Email: z.luo@yandex.com; Haiyan Luo. Department of Neurology Medicine, The Second Affiliated Hospital of Chongqing Medical University, Chongqing 400010, China. Email: haiyanluo@21cn.com.

Background: Parkinson's disease is the second major neurodegenerative diseases secondarily to Alzheimer's disease. Rapamycin is a fermentation product, which derived from Streptomyces hygroscopius. The aim of this study is to investigate the effect of rapamycin and its potential mechanisms on the acute attack of 1-methyl-4-phenyl-1,2,3,6-four hydrogen pyridine (MPTP) induced Parkinson's disease (PD) in mice.

Methods: PD model was established by intraperitoneal injection of MPTP for 5 days. The effect of intraperitoneal injection of rapamycin for treating the symptoms caused by PD was evaluated by behavior observation and HE pathological section. In order to understand the possible mechanism, immunofluorescence and immune precipitation mainly analyzes were used to measure the expression of critical protein p-4ebp1 in mammalian target of rapamycin (mTOR) signaling pathways in the striatum and substantia nigra.

Results: Rapamycin can effectively alleviate symptoms of PD. The levels of key protein p-4EBP1 in the striatum and substantia nigra were both significantly higher in PD group compared with control group $(\mathrm{P}<0.01)$, while being pretreated with rapamycin, the expression of $\mathrm{p}-4 \mathrm{EBP} 1$ in the striatum and substantia nigra were both decreased obviously $(\mathrm{P}<0.01)$.

Conclusions: p-4EBP1 protein may be involved in the pathogenesis of PD via mTOR signaling pathway. Inhibited mTOR-4EBP1 pathways could make a certain protective effect for the acute attack of PD induced by MPTP.

Keywords: Parkinson's disease (PD); p-4EBP1; rapamycin; mammalian target of rapamycin (mTOR); 1-methyl4-phenyl-1,2,3,6-four hydrogen pyridine (MPTP)

Submitted May 24, 2020. Accepted for publication Nov 22, 2020.

doi: 10.21037/apm-20-1096

View this article at: http://dx.doi.org/10.21037/apm-20-1096

\section{Introduction}

Parkinson's disease (PD) is the second major neurodegenerative diseases secondarily to Alzheimer's disease. Its main clinical manifestation is resting tremor, bradykinesia, myotonic rigidity, motion retardation, postural gait, and other behavior disorders. In the midbrain substantia nigra of Parkinson's patients, the level of autophagy was increased and the expression of autophagy- 
related protein was also increased, leading to autophagic apoptosis of neurons, dopaminergic neuron damage and degeneration. The etiology study of PD found that oxidative stress, mitochondrial failure, calcium overload, toxic effect of excitatory amino acids, apoptosis, immune abnormalities, and other mechanisms induced by the dysfunction of dopaminergic neurons are important pathological processes in the pathogenesis of PD, and which mainly involved in environment, genetic deficiency, aging and other potential mechanisms (1). However, the treatment of Parkinson's disease is under slow development. At present, researches of potential drugs are still not enough and there are still a lot of potential monomers needed for development, including natural monomers.

Rapamycin (Rapa) is a fermentation product, which derived from Streptomyces hygroscopius. It is approved by FDA as an immunosuppressant drug for prophylaxis of allograft rejection and is a well-known specific mammalian target of rapamycin (mTOR) inhibitor (2). Rapa targets several cellular functions such as proliferation, cell growth, autophagic cell death and exerts antioxidant defense through the inhibition of mTOR signaling pathway $(3,4)$. Recent studies have found that the signaling pathway of mTOR is involved in the pathological process of PD (5), but it is still not clear how mTOR signaling pathway is involved in the pathogenesis of PD.

It was reported that rotenone injections, which used to generate murine models of $\mathrm{PD}$, oppositely impacted TORC1 activity in different regions of mouse brains, increasing activity in the midbrain and decreasing activity in the striatum (6). What if a PD patient suffering from substantia nigra atrophy were treated with an mTORC1 inhibitor based on a rationale from data collected from hippocampal pathology? What if a frontotemporal dementia patient suffering from primarily temporal lobe pathologies was treated with an mTORC1-targeting drug based on frontal lobe data? As there is limited evidence to support that mTORC1 responds consistently to a wide range of interventions across brain regions, and some evidence to the contrary, it's responsible to not overgeneralize and assume globalized impact on the brain. More research needs to be conducted on the regional specific impacts of different mTORC1-directed interventions.

In this study, we mainly focused on the sporadic PD, which accounts for about $90 \%$ incidence of PD (7). The study use Rapa to pretreatment and block the signaling pathway of mTOR, to determine the role of the key protein
p-4EBP1 of mTOR signaling pathway in the sporadic PD through the changes in the behavioral and molecular pathological levels.

We present the following article in accordance with the ARRIVE reporting checklist (available at http://dx.doi. org/10.21037/apm-20-1096).

\section{Methods}

\section{Materials and reagents}

1-methyl-4-phenyl-1,2,3,6 four hydropyridine (MPTP) was obtained from Shanghai Xibao Biotechnology Co., Ltd.; Rapamycin, Anti-p-4EBP (Thr37/46) and anti-GAPDH were bought from Kang Cheng company; Goat Anti-Rabbit IgG ( $\gamma$-chain specific) and FITC-sheep anti mice were bought from Boshide Biotechnology Co., Ltd.; Rhodamine labeled Goat anti rabbit IgG was obtained from Zhongshan Jinqiao company; WB luminescent reagent provided from MILLIPORE company. Main instruments: Bio-Rad Doc 2000 gel imaging system, BECKMAN DU640 nucleic acid protein analyzer, frozen and paraffin slice machine (Swiss Laica company), HE dying Kit (Shanghai gfan Biology Technology Co., Ltd.).

\section{Animals}

Forty-eight SPF class male C57BL/6J mice weighing $22-25 \mathrm{~g}$ (age of 8 weeks) were selected. All animal experiments were performed after receiving the Chongqing Medical University of Medical Sciences Ethical Committee approval and in compliance with the principles of laboratory animal care (National Institutes of Health publication no. 85-23; revised, 1985) (No. 20170603). The mice were housed under standard conditions on $12 \mathrm{~h}$ light/12 h dark cycle in a temperature-controlled room $\left(21-22{ }^{\circ} \mathrm{C}\right)$ with frees access to food and water.

\section{Experimental design}

MPTP induced Parkinson's Disease model was established as previous study (8). The animals were randomly divided into 4 groups, 12 in each group. Group A is Rap + MPTP: mice were injected with rapamycin $(7.5 \mathrm{mg} / \mathrm{kg})$ for 7 days, twice a day, MPTP $(30 \mathrm{mg} / \mathrm{kg})$ was injected at $30 \mathrm{~min}$ after the administration of rapamycin at the day of 3 to 7 . Group $\mathrm{B}$ is Vehicle + MPTP: mice were injected vehicle with the same volume of rapamycin for 7 days, twice a day and 
injected MPTP $(30 \mathrm{mg} / \mathrm{kg})$ at $30 \mathrm{~min}$ like group A; Group $\mathrm{C}$ is Rap + Saline: mice injected with rapamycin for 7 days, twice a day, saline instead of MPTP was injected at $30 \mathrm{~min}$ after the administration of rapamycin at the day of 3 to 7 . Group D is Vehicle + Saline: mice were injected vehicle with the same volume of rapamycin for 7 days, twice a day and injected saline at $30 \mathrm{~min}$ like group $\mathrm{C}$.

\section{Preparation samples of brain tissue}

Harvest the brain tissue after the last injection $1 \mathrm{~h}$. Randomly selected 5 brain tissues of the mice in each group to make frozen section for HE staining and immunofluorescence detection. The whole brain tissues were fixed with $4 \%$ paraformaldehyde and then dehydrated with $2 \%$ sucrose, and cut the thickness of $5 \mu \mathrm{m}$ frozen section from the middle brain for the immunofluorescence and HE pathological examination.

The rest of the animals in each group were injected with $0.1 \%$ lidocaine $(1 \mathrm{mg} / \mathrm{kg})$ for anaesthesia, and harvest the whole brain tissue immediately on the ice (discard the cerebellum and olfactory bulb), then freezing in liquid nitrogen, and continue weighed and shredded, added to the lysate buffer solution, crushed, and centrifuged, collected the supernatant, and measured the protein concentration, and finally stored in the $-80^{\circ} \mathrm{C}$ refrigerator for use.

\section{HE staining}

The frozen section was stained with hematoxylin staining solution for $5 \mathrm{~min}$, then washed $10 \mathrm{~min}$ in the water to remove the excess dye solution, and use distilled water washed $10 \mathrm{~s}$ again, then soaked with $95 \%$ ethanol for 5 s. Then use Eosin staining dye stained $60 \mathrm{~s}$, washed with $70 \%$ ethanol for 2 times, dehydrated and transparent, then sealing the sections for image obtain.

\section{Immunofluorescence detection}

Incubate with anti-phospho-4EBP1 (Thr 37/46) antibody $(1: 100)$ overnight $(>8 \mathrm{~h})$ after repaired the antigen and serum blocked of the tissue section. Then washed the first antibody and incubated with the fluorescent labeled second antibody TRITC-IgG $(\mathrm{H}+\mathrm{L})$ (1:100) for $1 \mathrm{~h}$ at room temperature. Finally use $50 \%$ glycerol to seal the sections. And observed in the high field of fluorescence microscope, and take the same slice of brain tissue for magnified. The same area was chosen to compare the intensity of fluorescence signal in the same location.

\section{Western blot detection}

The protein samples were loaded in $10 \%$ electrophoresis gel, $120 \mathrm{~V}$ for $2 \mathrm{~h}$, then use PVDF membrane to transfer the protein to the membrane, use $5 \%$ non-fat milk to block $1 \mathrm{~h}$ in the room temperature. Then incubate with the first antibody anti-phospho-4EBP1 (Thr37/46) antibody at $4{ }^{\circ} \mathrm{C}$ for overnight with 1:1,000 dilution ratio. Next, washed with $1 \times$ TBST solution, 3 times, 15 min each time. And incubated with the second sheep anti rabbit antibody at room temperature for $2 \mathrm{~h}$, the washed with $1 \times$ TBST solution, 3 times, 15 min each time. Finally, the PVDF was soaked in the chemiluminescence reagent (MILLIPORE company Immobilon Western $100 \mathrm{~mL}$ ) for 1-3 min, and then exposure in the instrument of chemical reaction machine, and then scanning the gel image and image analysis (Bio-Rad, Gel Doc 2000).

\section{Statistical analysis}

The data were processed with the two factors variance analysis by SPSS17.0 software, and the measurement data were expressed with mean \pm standard deviation. $\mathrm{P}<0.05$ was statistically significant.

\section{Results}

\section{Bebavioral observation of the effect of Rapa on MPTP induced PD}

After 4 days of MPTP injection, the mice both in group Vehicle + MPTP and group Rapa + MPTP showed a typical Parkinson's disease, such as tremor paralysis and erect hair, foreleg elevation, vertical tail, movement decrease, slow motion and so on, compared to the group Rapa + saline and group Vehicle + saline $(\mathrm{P}<0.05$, Table 1$)$. While compared with the group of Vehicle + MPTP, the score of the climbing pole and suspension were significantly increased in the group of Rapa + MPTP $(\mathrm{P}<0.05)$. Furthermore, the score of paralytic shaking in group of Rapa + MPTP was obviously lower than that of Vehicle + MPTP group $(\mathrm{P}<0.05)$, which indicated that Rapa has a effect for MPTP induced PD.

\section{HE staining analysis}

In order to observe the pathological changes of brain 
Table 1 The behavioral observation of Rapa on MPTP induced PD (mean \pm SD, $\mathrm{n}=12$ )

\begin{tabular}{lcccc}
\hline Scores & Rapa + MPTP (group A) & Vehicle + MPTP (group B) & Rapa + Saline (group C) & Vehicle + Saline (group D) \\
\hline Climbing pole & $6.12 \pm 0.94^{\mathrm{b}, \mathrm{c}}$ & $5.12 \pm 1.02^{\mathrm{a}, \mathrm{d}}$ & $8.70 \pm 0.78$ & $8.70 \pm 0.78$ \\
Suspension & $2.05 \pm 0.43^{\mathrm{b}, \mathrm{c}}$ & $1.45 \pm 0.56^{\mathrm{a}, \mathrm{d}}$ & $2.89 \pm 0.50$ & $2.87 \pm 0.43$ \\
Tremor paralysis & $2.01 \pm 0.23^{\mathrm{c}}$ & $2.34 \pm 0.88^{\mathrm{d}}$ & $0.00 \pm 0.00$ & $0.00 \pm 0.00$ \\
\hline
\end{tabular}

${ }^{a}, \mathrm{P}<0.05$ vs. group $\mathrm{A} ;{ }^{b}, \mathrm{P}<0.05$ vs. group $\mathrm{B} ;{ }^{\mathrm{c}}, \mathrm{P}<0.05$ vs. group $\mathrm{C} ;{ }^{\mathrm{d}}, \mathrm{P}<0.05$ vs. group $\mathrm{D}$.

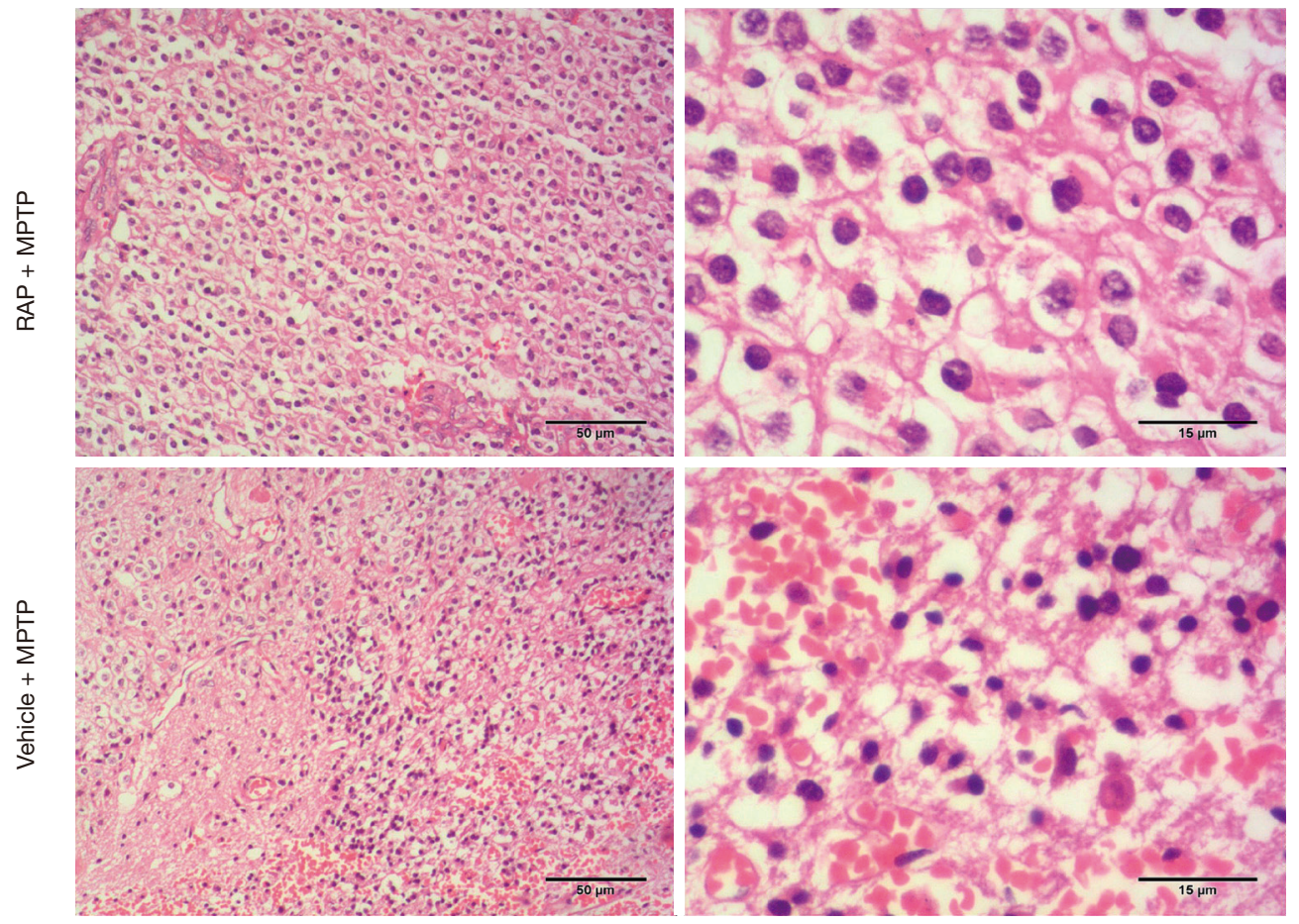

Figure 1 Effect of rapamycin for the structure of striatum on MPTP induced PD. The histopathological images (HE stain) were captured under the magnification of $\times 40$ and $\times 400$, respectively.

tissue by MPTP induced PD, we detected the pathological changes of striatum and substantia nigra to evaluate the effect of rapamycin for MTTP induced PD through HE staining. From Figure 1, we can see that there was an obvious bleeding and tissue edema in the striatum region of the Group B (Vehicle + MPTP), which lead to the significant decreased cell density in this area. While as shown in Figure 2, there was also showed an obvious tissue edema in Group B and the decreased cell density (black arrowhead marked edema). Conversely, Group A (Rapa + MPTP) significantly relieved tissue edema, and increased the cell density in the area of striatum and substantia nigra, respectively, compared to Group B (Vehicle + MPTP).

\section{Immunofluorescence assay for the expression of p-4EBP1 in MPTP induced PD}

Figure 3 shows the protein expression of p-4EBP 1 in substantia nigra and Figure 4 shows the protein expression of p-4EBP1 in striatum. From the results of immunofluorescence staining, we found that the protein expression levels of p-4EBP1 significantly increased in substantia nigra (Figure 3) and striatum (Figure 4) in the model group B (Vehicle + MPTP), compared with the control group D (Vehicle + Saline). While Rapa pretreatment group A (Rapa + MPTP) was significantly reduced the abnormal protein expression of $\mathrm{p}-4 \mathrm{EBP} 1$ in 

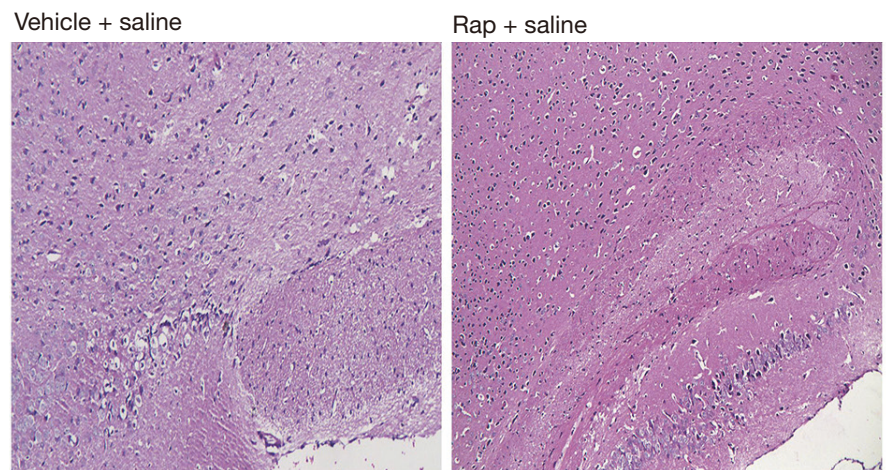

Rap + MPTP

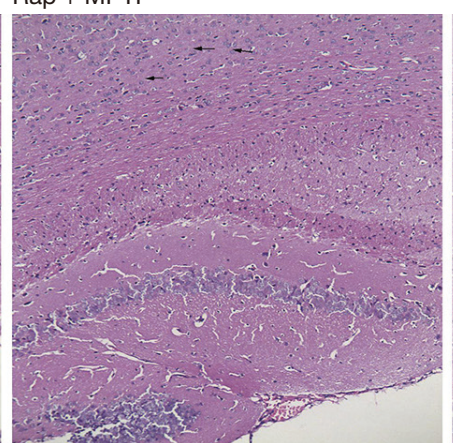

Vehicle + MPTP

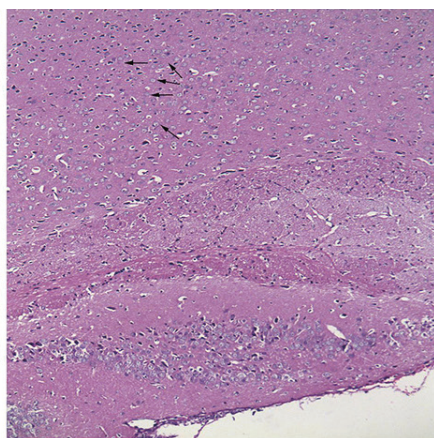

Figure 2 Effect of rapamycin for the structure of substantia nigra on MPTP induced PD. The histopathological images (HE stain) were captured under the magnification of $\times 200$.
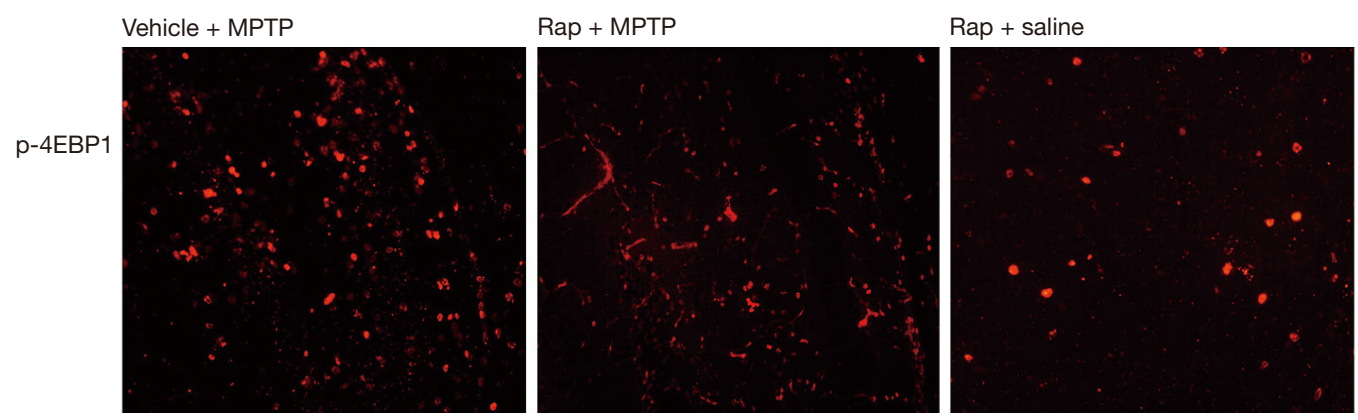

Vehicle + saline

Figure 3 The expression level of p-4EBP1 in striatal neurons for rapamycin pretreated PD model. The fluoresce images were obtained under the magnification of $\times 100$.
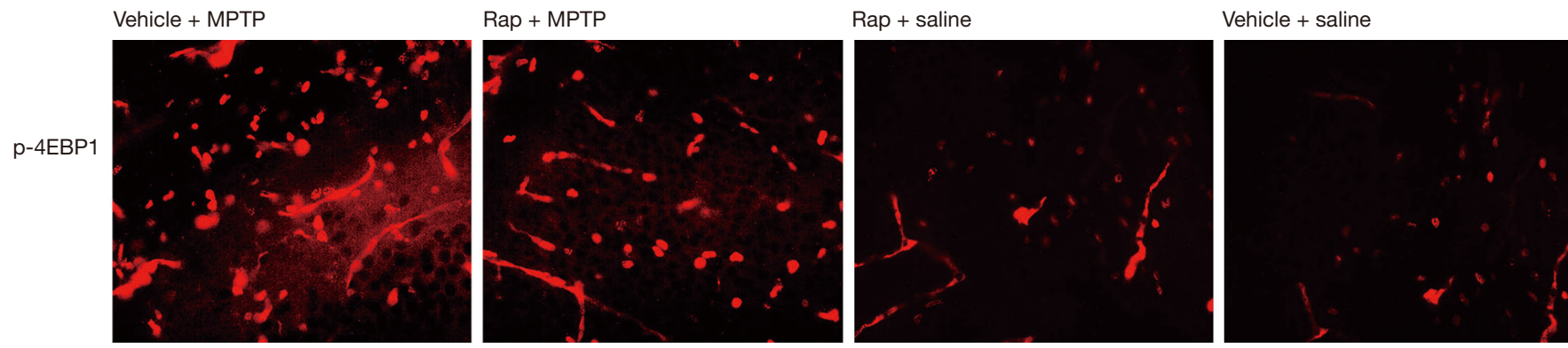

Figure 4 The expression level of p-4EBP1 in substantia nigra neurons for rapamycin pretreated PD model. The fluoresce images were obtained under the magnification of $\times 200$.

both substantia nigra (Figure 3) and striatum (Figure 4). In addition, pretreatment with Rapa did not affect the basal protein expression levels of $\mathrm{p}-4 \mathrm{EBP} 1$ in normal mice, compared with Group D (Vehicle + Saline).

\section{Western blotting detection the protein expression of p-4EBP1 in substantia nigra and striatum}

Furthermore, we detected the protein expression of p-4EBP1 in substantia nigra and striatum in the brain 


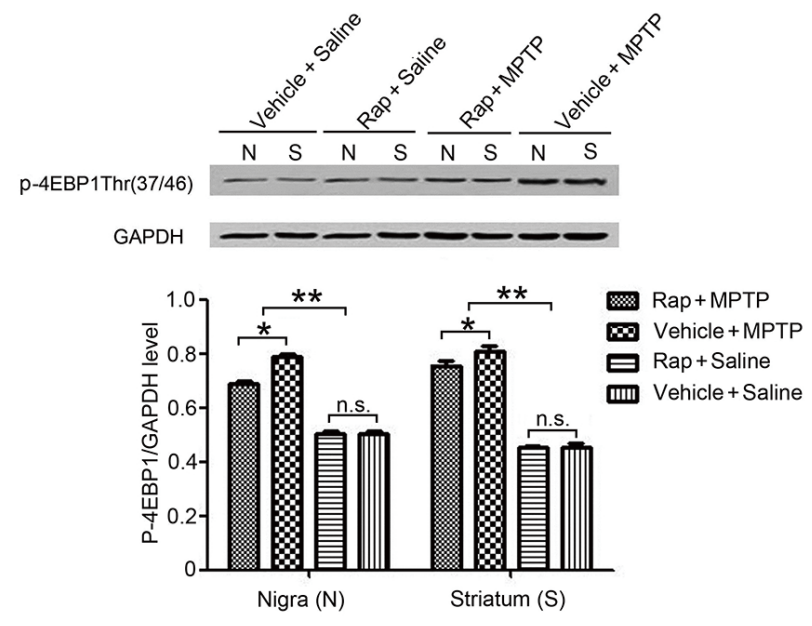

Figure 5 The expression levels of p-4EBP1 in the tissue of Substantia nigra and Striatum in different groups by western blot analysis. GAPDH was used as the internal control $\left(\mathrm{n}=12,{ }^{*} \mathrm{P}<0.05\right.$; ${ }^{* *} \mathrm{P}<0.01 ;$ n.s., no significance).

tissue of the mice by Western blotting technology (Figure 5). The results showed that the protein levels of p-4EBP1 significantly increased in the PD model group (Vehicle + MPTP) and the Rapa pretreatment model group (Rapa + MPTP), compared with the Rapa pretreated control group (Rapa + Saline) and the blank control group (Vehicle + Saline) $(\mathrm{P}<0.01)$. While, compare with the model group (Vehicle + MPTP), Rapa pretreatment model group (Vehicle + MPTP) was significantly inhibited the increase of the $\mathrm{p}-4 \mathrm{EBP} 1$ protein levels $(\mathrm{P}<0.05)$. And there was no significant difference in the protein levels of $\mathrm{p}-4 \mathrm{EBP} 1$ between the pretreated control group and the blank control group, as shown in Figure 5.

\section{Discussion}

mTOR plays an important role in cell growth and cell apoptosis. It is the central link for the control of the cell growth and cell proliferation, participates in biological processes such as gene transcription, protein translation, ribosome synthesis and so on. Inhibition of $\mathrm{mTOR}$ activity in low biological yeast and mammalian mice can prolong their life span (9-11). Oxidative stress is one of the important factors for inducing sporadic PD. From the cellular levels, the essence of the cell response to stress in vivo and in vitro is survival for their self (12-16). And the abnormal translation of proteins in cells is an important factor for leading to oxidative stress. Under the normal circumstances, the translation of proteins in cells is precisely regulated by various signaling pathways, especially in the initiation stage of the protein translation, which regulated by the factor of 4E (eIF4E). EIF4E, eIF4A and eIF4G were together constitute the eIF4F complex and are specifically associated with the 5'-terminal cap structure of the eukaryotic cell mRNA, participate in the translation of mRNA, and play the regulatory role of in the starting phase of the cap dependent translation $(17,18)$. EIF4E binding protein (4EBPs) can regulate the activity of eIF4E, and the activity of 4EBPs is strictly regulated by phosphorylation. The activation of mTOR leads to phosphorylation of 4EPB1, and phosphorylated 4EPB1 cannot be combined with eIF4E, causing eIF4E not to be inhibited by the transcriptional suppressor 4EBP1, but to bind to the 5' end of mRNA and initiate protein translation. The center of phosphorylation regulation of $4 \mathrm{EBP} 1$ is a conserved mTOR signaling pathway, including activation of PI3K/ AKT1 pathway and activation of mTOR in vivo. Therefore, mTOR phosphorylates 4EBP1, which further to promote the protein's translation. In summary, mTOR signals play a role in coordinating cell growth and altering physiological metabolism (19-22).

Rapamycin, as an inhibitor of mTOR, has the function of regulating mTOR signaling pathway. The study of the hereditary PD model showed that 4EBP1 and mTOR signaling pathway were involved in the pathogenesis and showed a certain protective effect (23-25). Parkin and PINK1 are the pathogenic genes of hereditary familial PD. In vivo and in vitro studies suggest that the treatment of rapamycin in parkin and PINK1 mutated mice can reduce the inhibitory effect of $4 \mathrm{EBP} 1$ on protein translation and thus produce a protective effect (26). The treatment of rapamycin in parkin and PINK1 mutant mice can significantly reduce the phosphorylation of 4EBP1 and improve the pathological phenotype of $\mathrm{PD}$, including muscle degeneration, mitochondrial damage, and exercise ability. While the continued administration of rapamycin after adulthood can completely improve the dopamine neuropathy. From gene and genetic aspects, LRRK2 homologue mutation of the Drosophila will produce a similar PD phenotype as that of parkin/PINK1 mutation. LRRK2 can regulate the activity of 4EBP1 $(9,26)$, and LRRK2 pathogenicity mutation can leads to a decrease in 4EBP1 phosphorylation in vivo, thereby reducing oxidative stress and degeneration in dopaminergic neurons (26,27). Take a together, 4EBP1 and rapamycin were all showed a 
protective effect in the above of the three PD models.

Activated Akt1 is an upstream regulator of 4EBP1, and Akt1 is activated by phosphorylation of upstream signal kinase. Some studies have shown that in parkin and PINK1 mutant Drosophila, the relative numbers of active Akt1 were decreased significantly, and further leading to the downregulation of the Akt $1 / \mathrm{mTOR}$ signaling pathway, which resulted in the down regulation of 4EBP1 activity and the inhibition of the total protein translation (28-33). mTOR regulates the inhibitory effect of 4EBP1 on translation initiation by phosphorylation, which can be inhibited by rapamycin. For the parkin and PINK1 mutant Drosophila, the Drosophila melanogaster depression, crawl retardation, muscle degeneration and mitochondrial damage can be improved and the degeneration of dopamine neurons can be completely inhibited by treated with rapamycin (34).

In this study, we found that rapamycin pretreatment can significantly improve the behavioral characteristics and reduce the p-4EBP1 levels in Parkinson mice. This decrease in p-4EBP1 may help activate the overall protein translation levels of the Parkinson model mice and improve the pathogenesis of sporadic PD. At present, p-4EBP1 and mTOR signaling pathways are involved in the research of PD, which mainly focusing on the heredity related familial PD. In our study, it is found that the mTOR and its downstream 4EBP1 signal not only participate in the pathogenesis of sporadic PD, but also plays a protective role, based on the relationship of the characteristics related to the environmental impact of most cases of Parkinson's disease. The mTOR inhibitor rapamycin can improve the Parkinson's phenotype of the PD mouse model in behavioral science, suggesting that mTOR may play a positive role in the prevention and control of sexual PD. And which may be a new target for the study of PD. More importantly, the previous study about inhibition of mTOR could relieve L-DOPA induced dyskinesia and the results of our currently study confirmed that the mTOR signaling pathway may be an important target for the treatment of Parkinson's disease (35). The main limitation of this study was that the results of this study was based on mice PD model, how was the validity in human was still needed to be further investigated.

\section{Conclusions}

In our study, we evaluated the protective effect of Rapa on the protein expression of $\mathrm{p}-4 \mathrm{EBP} 1$, and which may be involved in the pathogenesis of PD. In addition, inhibited of mTOR-4EBP1 pathways may make a certain protective effect for the acute attack of MPTP induced PD.

\section{Acknowledgments}

Funding: This study was supported by Chongqing Association for Science and Technology, CQAST (cstc2014jcyjA10065), Hospital Special Project of "Xinglin Scholar" of Chengdu University of Traditional Chinese Medicine in 2019 (No. YYZX2019073), Scientific Research Institute Performance Incentive and Guidance Special Project of Chongqing City (No. jxyn2020-5), and Science and Health Joint Medical Research Project of Chongqing City (No. 2019QNXM029).

\section{Footnote}

Reporting Checklist: The authors have completed the ARRIVE reporting checklist. Available at http://dx.doi. org/10.21037/apm-20-1096

Data Sharing Statement: Available at http://dx.doi. org/10.21037/apm-20-1096

Conflicts of Interest: All authors have completed the ICMJE uniform disclosure form (available at http://dx.doi. org/10.21037/apm-20-1096). The authors have no conflicts of interest to declare.

Ethical Statement: The authors are accountable for all aspects of the work in ensuring that questions related to the accuracy or integrity of any part of the work are appropriately investigated and resolved. All animal experiments were performed after receiving the Chongqing Medical University of Medical Sciences Ethical Committee approval and in compliance with the principles of laboratory animal care (National Institutes of Health publication no. 85-23; revised, 1985) (No. 20170603).

Open Access Statement: This is an Open Access article distributed in accordance with the Creative Commons Attribution-NonCommercial-NoDerivs 4.0 International License (CC BY-NC-ND 4.0), which permits the noncommercial replication and distribution of the article with the strict proviso that no changes or edits are made and the original work is properly cited (including links to both the formal publication through the relevant DOI and the license). See: https://creativecommons.org/licenses/by-nc-nd/4.0/. 


\section{References}

1. Jenner P. Oxidative stress in Parkinson's disease. Ann Neurol 2003;53 Suppl 3:S26-36; discussion S36-8.

2. Miller JL. Sirolimus approved with renal transplant indication. Am J Health Syst Pharm 1999;56:2177-8.

3. Foster KG, Fingar DC. Mammalian target of rapamycin (mTOR): conducting the cellular signaling symphony. J Biol Chem 2010;285:14071-7.

4. Ghasemnejad-Berenji M, Ghazi-Khansari M, Pashapour $\mathrm{S}$, et al. Synergistic effect of rapamycin and metformin against germ cell apoptosis and oxidative stress after testicular torsion/detorsion-induced ischemia/reperfusion in rats. Biomed Pharmacother 2018;105:645-51.

5. Abou-Sleiman PM, Muqit MM, Wood NW. Expanding insights of mitochondrial dysfunction in Parkinson's disease. Nat Rev Neurosci 2006;7:207-19.

6. Ramalingam M, Huh YJ, Lee YI. The Impairments of $\alpha$-Synuclein and Mechanistic Target of Rapamycin in Rotenone-Induced SH-SY5Y Cells and Mice Model of Parkinson's Disease. Front Neurosci 2019;13:1028.

7. Farrer MJ. Genetics of Parkinson disease: paradigm shifts and future prospects. Nat Rev Genet 2006;7:306-18.

8. Clark IE, Dodson MW, Jiang C, et al. Drosophila pink1 is required for mitochondrial function and interacts genetically with parkin. Nature 2006;441:1162-6.

9. Lau YS, Trobough KL, Crampton JM, et al. Effects of probenecid on striatal dopamine depletion in acute and long-term 1-methyl-4-phenyl-1,2,3,6-tetrahydropyridine (MPTP)-treated mice. Gen Pharmacol 1990;21:181-7.

10. Bonawitz ND, Chatenay-Lapointe M, Pan Y, et al. Reduced TOR signaling extends chronological life span via increased respiration and upregulation of mitochondrial gene expression. Cell Metab 2007;5:265-77.

11. Harrison DE, Strong R, Sharp ZD, et al. Rapamycin fed late in life extends lifespan in genetically heterogeneous mice. Nature 2009;460:392-5.

12. Bernal A, Kimbrell DA. Drosophila Thor participates in host immune defense and connects a translational regulator with innate immunity. Proc Natl Acad Sci U S A 2000;97:6019-24.

13. Kapahi P, Zid BM, Harper T, et al. Regulation of lifespan in Drosophila by modulation of genes in the TOR signaling pathway. Curr Biol 2004;14:885-90.

14. Teleman AA, Chen YW, Cohen SM. 4E-BP functions as a metabolic brake used under stress conditions but not during normal growth. Genes Dev 2005;19:1844-8.

15. Tettweiler G, Miron M, Jenkins M, et al. Starvation and oxidative stress resistance in Drosophila are mediated through the eIF4E-binding protein, d4E-BP. Genes Dev 2005;19:1840-3.

16. Yamaguchi S, Ishihara H, Yamada T, et al. ATF4-mediated induction of 4E-BP1 contributes to pancreatic beta cell survival under endoplasmic reticulum stress. Cell Metab 2008;7:269-76.

17. Richter JD, Sonenberg N. Regulation of cap-dependent translation by eIF4E inhibitory proteins. Nature 2005; 433:477-80.

18. Gingras AC, Raught B, Sonenberg N. eIF4 initiation factors: effectors of mRNA recruitment to ribosomes and regulators of translation. Annu Rev Biochem 1999;68:913-63.

19. Gingras AC, Raught B, Sonenberg N. Regulation of translation initiation by FRAP/mTOR. Genes Dev 2001;15:807-26.

20. Wullschleger S, Loewith R, Hall MN. TOR signaling in growth and metabolism. Cell 2006;124:471-84.

21. Holcik M, Sonenberg N, Korneluk RG. Internal ribosome initiation of translation and the control of cell death. Trends Genet 2000;16:469-73.

22. Clemens MJ. Translational regulation in cell stress and apoptosis. Roles of the eIF4E binding proteins. J Cell Mol Med 2001;5:221-39.

23. Tain LS, Mortiboys H, Tao RN, et al. Rapamycin activation of 4E-BP prevents parkinsonian dopaminergic neuron loss. Nature Neurosci 2009;12:1129-35.

24. King MA, Hands S, Hafiz F, et al. Rapamycin inhibits polyglutamine aggregation independently of autophagy by reducing protein synthesis. Mol Pharmacol 2008;73:1052-63.

25. Wyttenbach A, Hands S, King MA, et al. Amelioration of protein misfolding disease by rapamycin: translation or autophagy? Autophagy 2008;4:542-5.

26. West AB, Moore DJ, Biskup S, et al. Parkinson's diseaseassociated mutations in leucine-rich repeat kinase 2 augment kinase activity. Proc Natl Acad Sci U S A 2005; 102:16842-7.

27. Gloeckner CJ, Kinkl N, Schumacher A, et al. The Parkinson disease causing LRRK2 mutation I2020T is associated with increased kinase activity. Hum Mol Genet 2006;15:223-32.

28. Puig O, Marr MT, Ruhf ML, et al. Control of cell number by Drosophila FOXO: downstream and feedback regulation of the insulin receptor pathway. Genes Dev 2003;17:2006-20.

29. Southgate RJ, Neill B, Prelovsek O, et al. FOXO1 
regulates the expression of 4E-BP1 and inhibits mTOR signaling in mammalian skeletal muscle. J Biol Chem 2009;284:20440.

30. Murphy CT, McCarroll SA, Bargmann CI, et al. Genes that act downstream of DAF-16 to influence the lifespan of Caenorhabditis elegans. Nature 2003;424:277-83.

31. McElwee JJ, Schuster E, Blanc E, et al. Evolutionary conservation of regulated longevity assurance mechanisms. Genome Biol 2007;8:R132.

32. Giannakou ME, Goss M, Jünger MA, et al. Long-lived Drosophila with overexpressed dFOXO in adult fat body.

Cite this article as: Zhang G, Yin L, Luo Z, Chen X, He Y, Yu $X$, Wang $M$, Tian F, Luo H. Effects and potential mechanisms of rapamycin on MPTP-induced acute Parkinson's disease in mice. Ann Palliat Med 2021;10(3):2889-2897. doi: 10.21037/apm20-1096
Science 2004;305:361.

33. Hwangbo DS, Gershman B, Tu MP, et al. Drosophila $\mathrm{dFOXO}$ controls lifespan and regulates insulin signalling in brain and fat body. Nature 2004;429:562-6.

34. Imai $\mathrm{Y}$, Gehrke $\mathrm{S}$, Wang HQ, et al. Phosphorylation of 4EBP by LRRK2 affects the maintenance of dopaminergic neurons in Drosophila. EMBO J 2008;27:2432-43.

35. Santini E, Heiman M, Greengard P, et al. Inhibition of mTOR signaling in Parkinson's disease prevents L-DOPAinduced dyskinesia. Sci Signal 2009;2:ra36. 